\title{
Proximal endovascular blood flow shunt for thoracoabdominal aortic aneurism without total aortic clamping
}

\section{Desvio de fluxo sanguineo endovascular proximal para derivaçao cirúrgica de aneurisma toracoabdominal sem clampeamento total da aorta}

\author{
Gaudencio Espinosa, TCBC-RJ'; Rivaldo Tavares ${ }^{1}$; Fellppe FonseCa ${ }^{1}$; Alessandra Collares ${ }^{1}$; Marina Lopes ${ }^{1}$; Jose luis Fonseca ${ }^{1}$; \\ Rafael Steffan ${ }^{1}$
}

\section{A}

\begin{abstract}
The authors present a surgical approach to type III and IV Crawford aneurysms that does not need total aortic clamping, which allows the more objective prevention of direct ischemic damage, as well as its exclusion by the endoprosthesis implantation, shunting the flow to the synthetic graft.
\end{abstract}

Key words: Aortic Aneurysm, Blood Vessel Prosthesis. Endovascular Procedures. Mesenteric Ischemia.

\section{INTRODUCTION}

Eaced with the many advances in the surgical treatment Fof aortic aneurysms with involvement of visceral branches, there are still large morbidity and mortality related to the procedure. Among the most common complications, we highlight those inherent to the techniques employed, especially those related to total aortic occlusion (crossclamping). Approximately five decades ago, Etheredge et al. ${ }^{1}$ described the first case of abdominal aortic aneurysms with involvement of visceral branches successfully surgically corrected. Since then, the surgical technique has undergone significant changes, especially those carried out by Crawford et al. ${ }^{2}$, but the morbidity associated with crosscampling remained present. In this context, we emphasize the direct ischemic complications, largely dependent on the time of aortic clamping: injuries of the spinal cord, kidney and other abdominal viscera.

Over time methods appeared that sought to decrease ischemia caused by the crossclamping, including cardiopulmonary bypass and its variations (atrial-femoral bypass, hypothermic cardiac arrest, etc.), cerebrospinal fluid drainage, epidural cooling and induction of hypothermia. Although these approaches have proven some effectiveness in reducing complications, all refer to a way to minimize the insult caused rather than prevent it. Our aim is to describe a surgical technique without total aortic clamping, hence less likely to direct ischemic complications beyond endovascular bypass flow to the graft.

\section{TECHNIQUE}

We recommended to perform the procedure with the patient under general anesthesia and selective intubation of each main bronchus. In addition to the basic monitoring parameters (bladder catheter, capnography, thermometer, oximeter) continuous assessments of blood pressure and central venous pressure are important. The use of direct cardiac output monitors and intraoperative echocardiography must be individualized for each case, being at the anesthesiology service discretion.

For better understanding, the procedure is described separately in four stage:

First stage - The proposed access is the left thoracophrenolaparotomy with internal paramedian incision. A thoracotomy is performed at the level of the sixth intercostal space. The abdominal aorta is approached by the retroperitoneal route with en bloc lateral retraction of the visceral structures and peritoneal sac integrity. The thoracotomy is communicated with the laparotomy through the diaphragm radial section. To perform this operative time it is essential that the patient is under exclusive ventilation of the right lung. By that time it is interesting to mark the diaphragm edges with identifiable sutures to facilitate its closure later. The diaphragmatic incision is extended to the diaphragmatic crus, completely exposing the thoracoabdominal aorta path till its bifurcation. The employment of retractors is practically mandatory to maintain an adequate surgical field. The combination of a chest retractor (Finochietto) with an abdominal retractor

1. Serviço de Cirurgia Vascular, Hospital Universitário Clementino Fraga Filho, Universidade Federal do Rio de Janeiro (HUCFF-UFRJ) - RJ - Brazil. 
fixed to the table is satisfactory. After exposure of the aortic path, we must identify and repair the main visceral branches accessible to the left of the patient, including the celiac trunk, superior mesenteric artery and left renal artery. We also suggest that the Gerota's fascia under the left kidney is incised to release the kidney from the retroperitoneum, allowing proper kidney mobility, facilitating the manipulation of the aortic path and the reconstruction of renal flow. The maneuver also prevents the section of the left renal vein at the time of aneurysmectomy.

Second stage - With the aortic path and its main branches dissected and isolated, we proceed to the lateral clamping of the descending thoracic aorta with the Satinsky clamp (Figure 1). The partial isolation of the aorta allows the lateral aortotomy and proximal anastomosis with a bifurcated polyester prosthesis (eg: Dacron ${ }^{\circledR}$ ). Next, the forked ends of the prosthesis can be termino-laterally anastomosed to the common iliac, external iliac or even common femoral arteries, completing the aortic bypass. The distal arteries can sustain both total and lateral clamping for the anastomosis, the former being easier and faster to perform. It is important to note that there was no need for total aortic clamping to date. However, we emphasize that, for the technique to be implemented successfully, there must be a free aortic aneurysm segment after the left subclavian artery, so that the proximal anastomosis is possible (Figure 2). With the flow set between the aorta and the lower limbs, we turn our attention to the revascularization of the visceral branches. Despite the possibility of making a polyester or polytetrafluoroethylene (PTFE) bridge for revascularization of the celiac trunk, in most cases, the celiac trunk simple ligation will not bring major complications due to the extensive network of anastomoses with collateral branches. The superior mesenteric artery is routinely ligated and sectioned, being anastomosed directly (termino-terminal) or indirectly (termino-lateral) to a polyester or PTFE bridge brought from the bypass (Figure 3). For the anastomosis, the bypass graft is clamped laterally. Next, the same technical principles are used in the approach of the left renal artery (Figure 3).

Third stage - We perform a suture in tobacco pouch on the anterior aspect of the aortic graft, followed by a puncture and catheterization with introduction of rigid guide wire (eg: Amplatz $®$ ) extra support $0.035 \mathrm{~mm}-260 \mathrm{~cm}$ through which we introduce the $32 \times 20 \mathrm{~mm}$ aorto-uni-iliac conical stent deployment system. The endoprosthesis is deployed under direct palpation, between the healthy thoracic aorta segment and the bypass graft, completely bypassing the aortic flow and excluding the aneurysm from the proximal flow (Figure 4).

Fourth stage -We held a wide longitudinal opening of the aneurysmal sac (Figure 5A). The origin of the iliac arteries is identified and ligated in both ostia. The right renal artery ostium receives a termino-terminal anastomosis with an interposed polyester or PTFE bridge directly from graft, ending all visceral bridges (Figure 5B). Finally, we suture up the

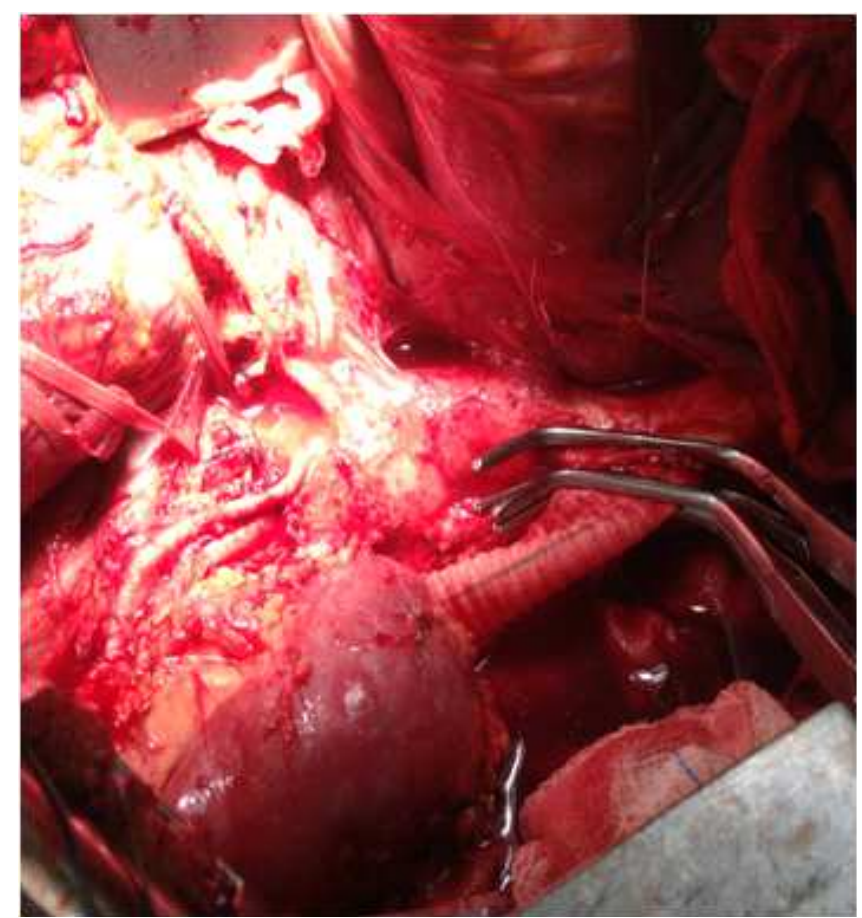

Figure 1 - Lateral clamping of the descending thoracic aorta. Note the termino-lateral anastomosis with the Dacron graft.

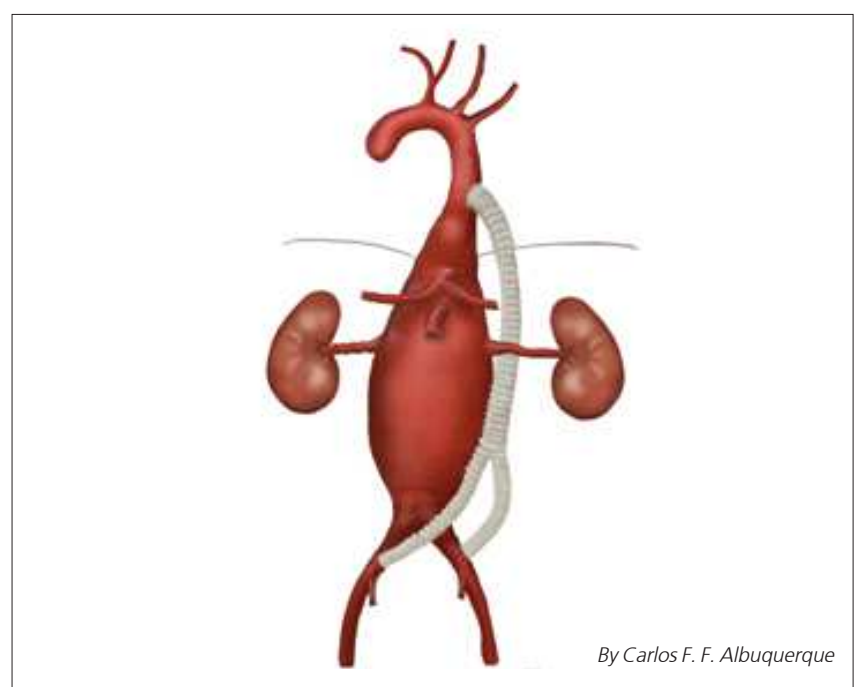

Figure 2 - $\quad$ Aortoiliac bypass with synthetic graft.

remaining stump of the descending thoracic aorta. Note that the stump will not be subjected to aortic pressures, since the main flow has been diverted by the implantation of the endoprosthesis. The procedure ends with the synthesis of the thoracophrenolaparotomy and left water seal thoracostomy.

\section{DISCUSSION}

The treatment of thoracoabdominal aneurysm still has high morbidity and mortality despite advances in 


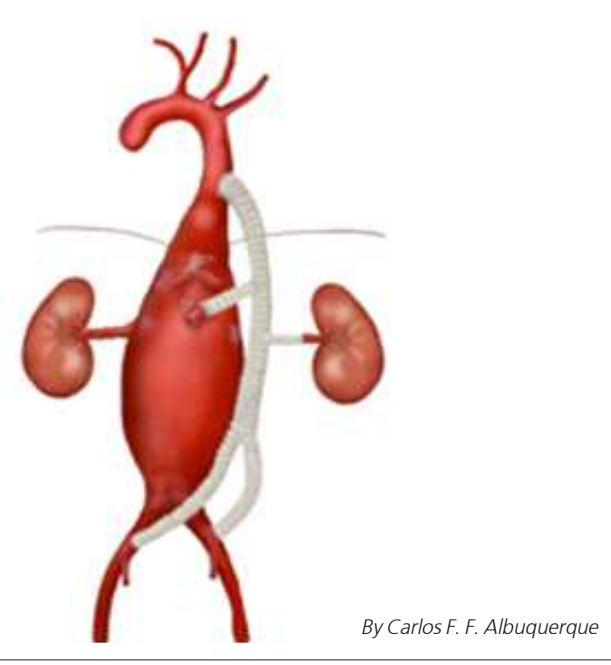

Figure 3 - Bridges to the superior mesenteric and left renal arteries.

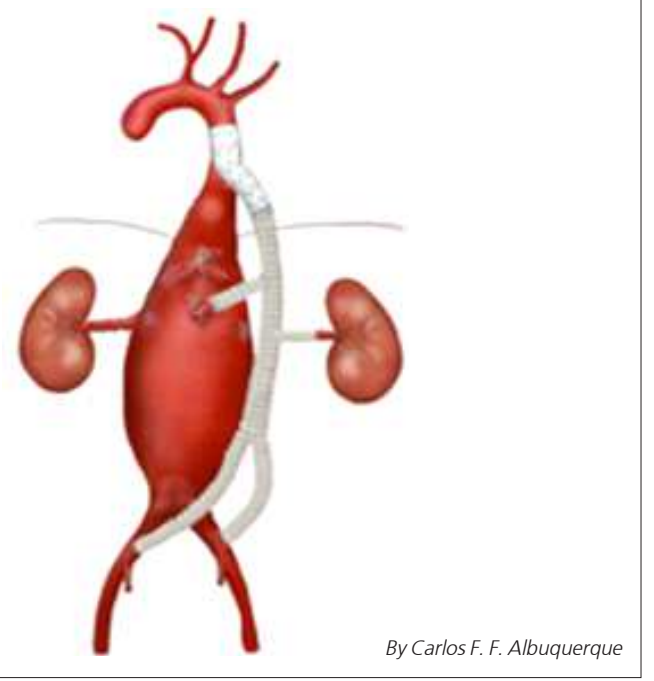

Figure 4 - Blood flow shunt by implant of an endoprosthesis.

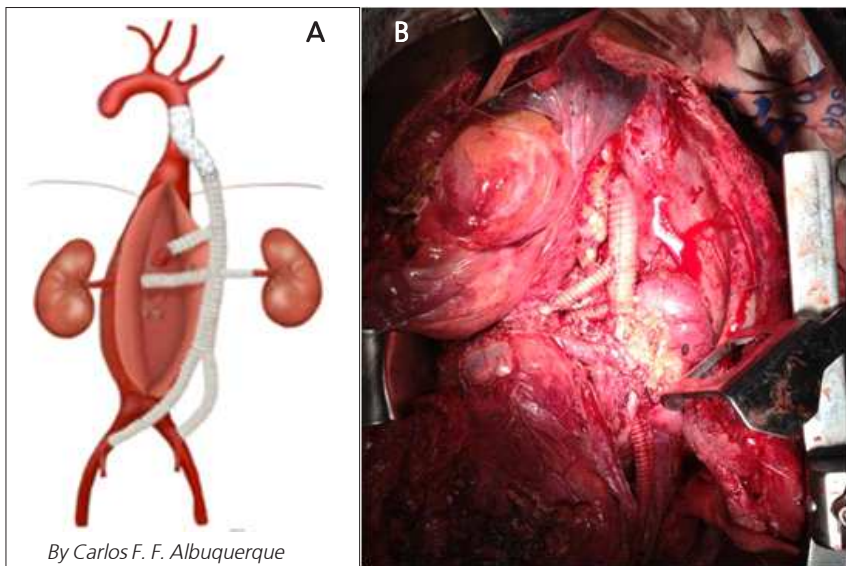

Figure 5 - $\quad$ Opening the aneurysm sac (A) with manufacturing of bridges to the superior mesenteric and right renal arteries (B). techniques developed and discussed in the past 30 years in trying to minimize major complications: spinal cord ischemia, visceral ischemia, kidney failure, perioperative hypotension, need for multiple transfusions, among others. The technique described by us aims to minimize this damage in thoracoabdominal aneurysms of Crawford's $\mathrm{s}^{2}$ types III and $\mathrm{N}$, through the possibility of lateral aortic clamping, providing full flow, which is maintained throughout the procedure, avoiding greater hemodynamic instability, need of cardiopulmonary bypass (CPB), measures to prevent spinal cord ischemia and visceral hypoperfusion.

Preoperative evaluation is also important to estimate the risk of developing postoperative renal failure. According to Schepens et al. ${ }^{3}$, preoperative age and serum creatinine are predictive variables of the postoperative dialysis need. Yang et al. ${ }^{4}$ state that a time of renal ischemia greater than 25 minutes and the crossclamping are significant risk factors for the development of postoperative renal failure. In the lateral clamping technique described by us, renal ischemia time is restricted only to the time of manufacturing of the bridge to the renal artery.

The maintenance of perfusion distal to the total clamping has proved a necessity. Most authors cite the alternative use of CPB, celiac trunk and mesenteric catheterization with continuous infusion of nourishing solution and infusion of cold solution in the renal arteries is while the visceral branches anastomoses are performed ${ }^{5}$. Our strategy also renders CPB or solutions infusion unnecessary, the manufacturing time of the bridges to the visceral arteries being considered tolerable. The hybrid technique is also referred, mainly indicated in patients with high surgical risk, with direct bridges from the iliac vessels to the visceral vessels and subsequent endovascular aneurysm exclusion, thus avoiding the use of CPB and also the total clamping ${ }^{6}$. However, mores studies are needed to confirm the long-term benefits and safety of the hybrid procedures $^{6,7}$.

Conrad et al. showed that the mortality of patients who developed paraplegia or paresis was significantly higher than in those who did not develop them ${ }^{8}$. Thus, they recommend renal hypothermia via catheterization and cold solution infusion, epidural cooling and reconstruction of intercostal arteries, guided by continuous monitoring (motor-evoked potentials), and CPB.

The axilofemoral bypass is also a surgical option?, which has the advantage of reducing afterload, lower incidence of spinal cord ischemia and preservation of visceral flow $^{10}$. Although effective, this strategy significantly increases operating time. The aorto-bi-iliac bypass already performed in our technique allows for distal perfusion and reduces operative time.

Cambria et al. demonstrated a reduction in spinal cord ischemia in the open treatment of thoracoabdominal aneurysm (ATA) through epidural cooling and observed that mortality doubles in the postoperative period of non-elective 
surgeries ${ }^{11}$. The demonstrated lateral clamping allows spinal cord perfusion during the entire procedure until the moment of flow bypass with the endoprosthesis implantation.

In summary, the conventional approach to ATA is still widely used, especially in non-elective conditions, for endovascular treatment failure and in complex ${ }^{12}$ or infection cases. Moreover, the superiority of the hybrid technique in endovascular treatment over the conventional technique has not been proven ${ }^{13,14}$. Thus, we believe that the procedure has current utility and its main advantage is to maintain distal flow and shorter visceral ischemia, resulting in the reduction of postoperative morbidity and mortality. This fact stimulates new studies to evaluate the described benefits.

\section{R E S U M O}

Os autores apresentam uma abordagem cirúrgica aos aneurismas do tipo III e IV de Crawford em que não é necessário o pinçamento total da aorta, o que permite a prevenção do dano isquêmico direto de forma mais objetiva, assim como sua exclusão por implante de endoprotese desviando o fluxo para o enxerto sintético.

Descritores: Aneurisma Aórtico. Prótese Vascular. Procedimentos Endovasculares. Isquemia Mesentérica.

\section{REFERENCES}

1. Etheredge SN, Yee J, Smith JV, Schonberger S, Goldman MJ. Successful resection of large aneurysm of the upper abdominal aorta and replacement with homograft. Surgery. 1955;38(6):107181.

2. Crawford ES. Thoraco-abdominal and abdominal aortic aneurysms involving renal, superior mesenteric, celiac arteries. Ann Surg. 1974;179(5):763-72.

3. Schepens MA, Defauw JJ, Hamerlijnck RP, Vermeulen FE. Risk assessment of acute renal failure after thoracoabdominal aortic aneurysm surgery. Ann Surg. 1994;219(4):400-7.

4. Yang SS, Park KM, Roh YN, Park YJ, Kim DI, Kim YM. Renal and abdominal visceral complications after open aortic surgery requiring supra-renal aortic cross clamping. J Korean Surg Soc. 2012:83(3):162-70

5. Hou Y, Zhao J, Guo W, Huang S, Wang C. Surgical repair of thoracoabdominal aortic aneurysms using the critical artery reattachment technique. J Biomed Res. 2011;25(3):220-3.

6. Chiesa R, Civilini E, Melissano G, Logaldo D, Calliari FM, Bertoglio L, et al. Management of thoracoabdominal aortic aneurysms. HSR Proc Intensive Care Cardiovasc Anesth. 2009;1(1):45-53.

7. Carrel TP, Signer C. Separate revascularization of the visceral arteries in thoracoabdominal aneurysm repair. Ann Thorac Surg. 1999;68(2):573-5.

8. Conrad MF, Ye JY, Chung TK, Davison JK, Cambria RP. Spinal cord complications after thoracic aortic surgery: long-term survival and functional status varies with deficit severity. J Vasc Surg. 2008;48(1):47-53.

9. Comerota AJ, White JV. Reducing morbidity of thoracoabdominal aneurysm repair by preliminary axilofemoral bypass. Am J Surg. 1995;170(2):218-22.
10. Conrad MF, Ergul EA, Cambria MR, Lamuraglia GM, Simon M, Cambria RP. Evolution of operative strategies in open thoracoabdominal aneurysm repair. J Vasc Surg. 2011;53(5):1195201.

11. Cambria RP, Clouse WD, Davison JK, Dunn PF, Corey M, Dorer D. Thoracoabdominal aneurysm repair: results with 337 operations perfomed over a 15-year interval. Ann Surg. 2002; 236(4):4719; discussion 479

12. LeMaire SA, Green SY, Kim JH, Sameri A, Parenti JL, Lin PH, et al. Thoracic or thoracoabdominal approaches to endovascular device removal and open aortic repair. Ann Thorac Surg. 2012;93(3):72632; discussion 733 .

13. Tshomba Y, Bertoglio L, Marone EM, Melissano G, Chiesa R. Visceral aortic patch aneurysm after thoracoabdominal aortic repair: conventional vs hybrid treatment. J Vasc Surg. 2008;48(5):108391.

14. Greenberg RK, Lu Q, Roselli EE, Svensson LG, Moon MC, Hernandez AV, et al. Contemporary analysis of descending thoracic and thoracoabdominal aneurysm repair: a comparison of endovascular and open techniques. Circulation. 2008;118(8):80817.

Received on 07/03/2014

Accepted for publication 15/04/2014

Conflict of interest: none.

Source of funding: none.

\section{Address for correspondence:}

Gaudencio Espinosa

E-mail: g.espinosa@uol.com.br 